\title{
Researching English L2 writing in international higher education
}

\author{
Jim McKinley
}

\begin{abstract}
While socially-situated English L2 writing education has been explored in great depth in thousands of studies, less research has been done on the impact of the international higher education context on the phenomenon. In our increasingly globalised world, international uses of English are on the rise in academic writing, putting into question native speaker standards and norms, which handily problematizes the entire research area. The research topics and questions in this paper consider English L2 writing from an international higher education perspective that challenges much of what we may have understood about phenomena in this area.
\end{abstract}

\section{My professional experience and area of expertise}

English L2 writing in an international higher education context has been a central research focus throughout my career. In my early days teaching on a TESOL master's programme, I found students struggling to shift from formulaic, basic, grammatically accurate writing, to university writing requiring original contributions to knowledge, and an original voice. After many, many years of contemplation, I produced a conceptual piece on contrastive rhetoric (McKinley, 2013). My thinking on the topic then moved to a consideration of how a social constructivism paradigm (McKinley, 2015), and awareness of metalanguage in argumentative writing (McKinley, 2018) might help to understand university English L2 critical argument and writer identity. As a PhD programme director and supervisor of many master's and doctoral projects in TESOL, I've found that students succeed when they write about a familiar topic, questioning everything they believe to be true about it, and challenging these beliefs using knowledge gained in their higher degree studies. It is the higher education context that will serve as the general area from which I situate my recommendations for $\mathrm{L} 2$ writing research in this chapter.

\section{How to choose a research topic}

Master's students of TESOL need to be practical when choosing their topics. They need to be realistic: the dissertation is short, and the time to conduct the study and write the dissertation is short. Simple is best. The topics, and their questions, need to lend themselves well to appropriate research designs. Far too often, I come across master's dissertations where the topic and questions are ill-formed, and the study, involving interviews with a handful of friends, shows little to no evidence that the student understands research and is deserving of the degree. Also frustrating is when students draw conclusions on their topics, including implications for 'better teaching', 'improvements' or 'fixing' the programmes students came from, before the study even took place. A good topic is based on a problem the student has experienced, but the process of the inquiry needs to reflect a holistic perspective, incorporating the taught parts of the degree before drawing any conclusions.

These same considerations are also important at the doctoral level. While doctoral students have a longer period of time to undertake a more substantial piece of work, they need to work within the finite time and word limitations available to them. A doctoral study should be seen as an exercise in research, where candidates demonstrate their ability to conceive, design, conduct and report on an original contribution to knowledge. It does not need to achieve dramatic impact that is more 
typically achieved over a longer body (sometimes a lifetime) of work, which can be continued after graduation as they embark on independent research careers.

Choosing the right topic is a reflexive process. First, a good topic will be familiar - one from experience. This topic will also be filled with questions about how and why. It can be based on either a language teaching or learning experience, or both. Next, the topic needs to be questioned in a way that does not produce answers. These are the answers to 'discover' through research inquiry. Assumed outcomes of the study need to be reformulated into questions. Good questions will avoid 'fixing' a perceived problem, and instead explore the possibility of a problem. Such questions lend well to qualitative inquiry. Finally, the topic should be socially situated, taking into consideration contextual factors that will impact the research design.

Of utmost importance in consideration of topic choice is recognising that a qualitative study does not mean the study must involve human participants. A good topic will lend itself well just as easily to interviews and observations as it would to other qualitative approaches, such as systematic reviews of literature, document analysis, or corpus studies.

\section{Suggested current research topics}

While socially-situated English L2 writing education has been explored in great depth in thousands of studies, less research has been done on the impact of the international higher education context on the phenomenon. And in our increasingly globalised world, international uses of English are on the rise in academic writing, putting into question native speaker standards and norms (see McKinley \& Rose, 2018), which handily problematizes the entire research area. The five research topics below all consider English L2 writing from an international higher education perspective that challenges much of what we may have understood about phenomena in this area.

\section{Topic 1: Standards and norms in English L2 writing}

Academic writing is generally considered less amenable to variation and change than spoken language. But when it comes to English academic writing, as an academic lingua franca with a large majority of writers using L2 English, we are currently witnessing substantial challenges to the standards and norms that have been maintained as synonymous with native fluency. In a study of the author guidelines of academic journals (McKinley \& Rose, 2018), the guidelines were often found to specifically position L2 writers as deficient of 'native' standards. The study demands a discussion surrounding the need to decouple good academic English writing from concepts such as nativeness. We are at a time now where it is unethical to maintain so-called 'native speaker norms'. We need to encourage all authors to write using an English that can easily be understood by a broad, heterogeneous, global, and multilingual audience. This topic draws into question both teaching and assessment practices involving English L2 writers in international higher education, in consideration of potentially unethical deficiency models of such writers.

\section{Topic 2: Social constructivism in English L2 writing education}

If we understand academic writing to be socially situated, we should consider, then, in what ways knowledge is socially constructed through English L2 writing education. We should consider how the interrelationship between the elements of cultural practices in academic discourse and writer 
identity is influenced by the sociocultural values of academic discourse. We have an opportunity to problematize the interrelationship by viewing English $L 2$ writing through a social constructivist lens, inquiring into how thinking processes are shaped by awareness of the social nature of academic discourse, and how this thinking arises from a writer identity that fits in with the culture of English academic writing. Using social constructivism as an analytical framework for English L2 writing (e.g. McKinley, 2015), this topic targets the context of learning at the classroom, university, as well as broader cultural level, raising questions regarding the impact of context at these different levels on English L2 writers' identity development.

\section{Topic 3: Critical thinking and/or pragmatics in English L2 writing}

L2 learners' critical thinking in academic writing has been challenged in the literature. The questions draw on issues related to contrastive rhetoric, as well as studies in pragmatic competence. In a conceptual paper on contrastive rhetoric (McKinley, 2013), it is argued that criticisms of English L2 writing learners' ability to think critically are misguided, and a set of suggestions is offered for positive development of critical thinking that serve as ideal points to challenge through studies in other contexts. On pragmatics in English L2 writing, still little research has been done in this area, as most pragmatics studies target speaking. Zhau and Kaufer's (2013) study investigating the use of a pragmatic assessment tool in $\mathrm{L} 2$ writing classroom challenges criticisms of English L2 writers' pragmatic competence by targeting discourse-level pragmatic behaviours in L2 writing. While their study incorporated significant quantitative data, their analysis suggests potential in conducting qualitative research in this area. Furthermore, research development in the area of English as a lingua franca has put the relevance of studies in pragmatics at risk, making it an especially current topic of inquiry.

\section{Topic 4: Use of metalanguage in supporting English L2 writing}

English L2 writing teachers and students may benefit from being provided with explicit metalanguage for the social construction of writerly selves. Support for this is found in the hundreds of studies that have used Hyland and Tse's (2004) framework for identifying such metalanguage. In my own study developing a framework for this purpose (McKinley, 2018), the findings suggest that struggles students face to meet their teachers' expectations of their writing could potentially be alleviated if both teachers and students were aware of the metalanguage used by student writers in establishing their writer identities, and by teachers when assessing students'

writing. Such a suggestion requires further inquiry, to investigate the impact of an awareness of this language on both students and teachers. The idea of explicitly addressing writer identity in English L2 writing education has been contested in the literature as unhelpful for learners who need to stay focused on the basics of academic writing.

\section{Topic 5: Assessment and/or washback in English L2 writing education}

Research into assessing English L2 writing has focused a great deal on different types of, and attitudes toward, feedback, especially grammar correction. Assessment is often a major concern for students and teachers alike, and as the assessment of writing is notoriously vague, subjective, and difficult to quantify, it is a valuable topic for qualitative inquiry. In exam-based educational cultures, concerns about feedback are secondary to the bigger issues of 'teaching to the test', known as the washback effect (see McKinley \& Thompson, 2018). Because assessment is such a major concern, 
teachers might find themselves leading exam preparation rather than targeting the development of sustainable skills, known as negative washback. There is also positive washback, when teaching to the test leads to the development of sustainable skills. Especially in international higher education, the impact of testing and assessment is one worth exploring, as research into international uses of English have problematized the area even further.

\section{Research questions on English L2 writing in international higher education}

- How open are learners and teachers to non-standard uses of English in L2 writing? This question targets attitudes of key stakeholder attitudes towards Englishes in written modes of communication.

- How do attitudes to non-standard Englishes vary across types of writing? This question builds on the first research question by exploring differences between specific registers and genres of written communication.

- How could standards and norms of English writing be challenged in language curricula to reflect global uses of English? This question requires action research, field research, or teacher/learner narratives to uncover classroom practices that succeed in delivering a global perspective of English use.

- How socially situated (or, how much social interaction) is English L2 writer education, and what influence does this have on learners' writer identity? As education is highly contextualised, there is a need to explore the influence of various classroom environments and pedagogies on $\mathrm{L} 2$ writer development including writer identity.

- What influences (both positive and negative) does the L1 have on L2 writing development? This research question targets contrastive rhetoric and the role of the L1 in L2 writing development, investigating linguistic and cultural differences between the two languages.

- How is pragmatic competence developed in English L2 writing education? Pragmatic competence in L2 writing has been less explored. There is opportunity to consider English as a global lingua franca, which challenges relevance of native-benchmarked pragmatic competence.

- How can awareness of metalanguage support English L2 writing teachers' feedback? This research question requires analysis frameworks or systems to identify metalanguage for L2 writing teachers to better understand students' intentions in their writing.

- How can English L2 writing students and teachers use metalanguage to understand writer identity use in appropriate and effective written arguments? This question uses a focus on using metalanguage to make instruction explicit about L2 writer identities. This idea has been contested in the literature, making it a worthy area of inquiry.

- How do assessment practices influence English L2 writing education? This is a potentially valuable area for qualitative inquiry as the subjective nature of assessment of writing makes it difficult for students to understand.

- How is evidence of a washback effect dealt with English L2 writing education? The washback effect of testing in ELT is an area of great debate, and investigating the effect in English L2 writing education provides a useful framing of the issue.

\section{References}

Hyland, K., \& Tse, P. (2004). Metadiscourse in academic writing: A reappraisal. Applied Linguistics, 25(2), 156-177. 
McKinley, J. (2013). Displaying critical thinking in EFL academic writing: A discussion of Japanese to English contrastive rhetoric. RELC Journal, 44(2), 195-208.

McKinley, J. (2015). Critical argument and writer identity: Social constructivism as a theoretical framework for EFL academic writing. Critical Inquiry in Language Studies, 12(3), 184-207.

McKinley, J. (2018). Integrating Appraisal Theory with possible selves in understanding university EFL writing. System, doi: 10.1016/j.system.2018.07.002.

McKinley, J. \& Rose, H. (2018). Conceptualizations of language errors, standards, and norms in English for research publication purposes: An analysis of journal submission guidelines. Journal of Second Language Writing, in press.

McKinley, J. \& Thompson, G. (2018). "Washback effect in teaching English as an international language", In Liontas, J. I. (Ed.) The TESOL Encyclopedia of English Language Teaching (1st ed.). Project Editor: DelliCarpini, M.; Volume Editor: Abrar-ul-Hassan, S. Hoboken, NJ: Wiley.

Zhao, H., \& Kaufer, D. (2013). DocuScope for genre analysis Potential for assessing pragmatic functions. In Taguchi, N. \& Sykes, J. M. (Eds.) Technology in Interlanguage Pragmatics Research and Teaching (pp. 235-260). Amsterdam: John Benjamins. 